Original Article

\title{
Cross Sectional study to asses housing conditions and to compare it with education and socio economic status of a semi urban area in Mangalore : A Pilot study
}

\author{
Sudharani M. ${ }^{1}$, Rashmi Kundapur', K.G. Kiran ${ }^{3}$ \& N. Udaya Kiran ${ }^{4}$ \\ ${ }^{1}$ Postgraduate, ${ }^{2,3}$ Associate Professors, ${ }^{4}$ Professor $\&$ HOD, Department of Community M edicine, \\ K.S. Hegde M edical Academy, M angalore, Karnataka, India. \\ Correspondence \\ Sudharani M. \\ Department of Community Medicine, K.S. Hegde Medical Academy, Nitte University, M angalore 575018, Karnataka, India \\ E-mail : drsudhanarayan@gmail.com
}

\begin{abstract}
Introduction : Poverty imposes an oppressive weight on India, especially in the rural areas where almost three out of four Indians and 77 percent of the Indian are under poor living conditions. Although poverty has been reduced during the past four decades, it remains painfully high .Provision of adequate housing and amenities are major challenges for human development, particularly among lowincome urban households in developing countries. Often this shortfall is evident from the proliferation of slums and squatters. .
\end{abstract}

Objectives: 1. To assess the housing conditions of the semi urban area (Field practice area of KS Hegde M edical Academy).

2. To associate these housing conditions with Education and Socio Economic Status.

Methodology : Forty houses included under GRAM A KSHEM A project (Field practice area of KS Hegde M edical Academy) were selected. A pilot study with questionnaire to asses housing condition was done. Subjects were interviewed for their education and socioeconomic status.

Results: $100 \%$ of Graduates, post graduates and Professionals have excellent housing conditions. Poor housing conditions was seen as the level of education decreased to high school and post high school. Housing conditions were excellent as the socioeconomic class increased. $66.6 \%$ of Class I population has excellent housing conditions. $63 \%$ of Class II population has good housing conditions and $38.5 \%$ of Class IV population has poor housing conditions.

Conclusions: It was found that majority of the population had good housing conditions. Education and Socio economic status has an impact on Housing condition.

Key words: Housing Condition; Education; Socio Economic Status.

\section{Introduction}

Housing is the basic requirement of Human wellbeing. Housing condition as a whole includes type of dwelling unit, drinking water, sanitation, drainage, etc. ${ }^{1}$ Adequate housing is recognised as a basic human right by the United Nations and its constituent bodies. ${ }^{2}$ National Sample Survey Office under the Ministry of Statistics and

Access this article online
Quick Response Code

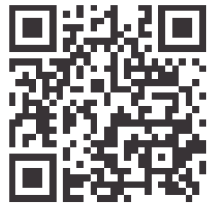

P $r$ o g $\mathrm{g}$ a $\mathrm{m}$ m e Implementation, Government of India has been carrying out nationwide socioeconomic surveys covering various subjects on a regular basis. ${ }^{3}$ Next to
Food and Clothing Housing is considered the basic need of humans both from social and economic point of view. Hence information regarding housing is considered as one of the key indicator for socio-economic development. ${ }^{3}$ The urban poverty apart from being distinct from rural poverty also has another dimension which reveals that the problems being faced by the poor in small urban areas are different from that of large cities. However, in general, the urban poverty manifests in the form of inadequate provision of housing and shelter, water, sanitation, health, education, social security and livelihoods along with special needs of vulnerable groups like women, children, differently able and aged people. Most of the poor are involved in informal sector activities where there is constant threat of eviction, removal, confiscation of goods 
and almost non-existent social security cover. Even when segments of the urban population are not income-poor, they face deprivation in terms of lack of access to sanitary living. Settlements comprising modest houses conditions and their well-being is hampered by discrimination, social exclusion, crime, violence, insecurity of tenure, hazardous environmental conditions and lack of voice in governance.Poor people in most urban areas are forced to live in cramped, overcrowded and unsanitary conditions, and are highly dependent on public bodies to provide goods and services (water, health care, regulation of job contracts etc). This is not from choice, but because they have much less control over their immediate environment than in rural areas. Options for support from family and community based networks and safety net systems (developed over generations in rural villages) are almost non-existent. ${ }^{4}$

Most of the urban poor live in deplorable housing conditions with high implicit and explicit costs of housing. The Census 2011data reveals that 32.1 percent live in one room house.Over 40 studies were found on the impact of overcrowding on the physical health of adults and children.The studies suggest that there may be an independent relationship between overcrowding and child mortality, but the evidence is limited.Evidence from good quality large scale studies point to a relationship between overcrowding in childhood and respiratory conditions in adulthood, but affecting children differently depending on age. ${ }^{4}$

Another major problem the urban poor face is the lack of legal entitlements on property and assets. ${ }^{5}$

In the urban areas, the poor face a lack of access to quality education which results in higher proportions of the monthly income of the urban poor being spent on basic education for their children. It also results in the filtering out of female children from secondary education with the drop-out rates of female students at the secondary level being very high. ${ }^{5}$

SES consists of many dimensions which relate to health in different ways.Different measures of SES may operate in different ways, and it is useful to explore these mechanisms precisely. Example, short term fluctuations are noted if income is used to measure the SES. Education tends to remain stable throughout adulthood so these patterns would not be observed if one used education as a measure of SES. ${ }^{6}$

The health benefits of education also flow intergenerational. Better-educated parents and especially mothers have healthier children, ${ }^{7,8}$ and these children grow up to be healthier adults. ${ }^{9}$

Open dumpsite approach as solid waste disposal method is a primitive stage of solid waste management in many parts of the world. It is one of the most poorly rendered services by municipal authorities in developing countries as the systems applied are unscientific, outdated and in- efficient. Solid waste disposal sites are found both within and on the outskirts of developing urban cities. With in-crease in the global population and the rising demand for food and other essentials, there has been a rise in the amount of waste being generated daily by each house- hold. This waste is ultimately thrown into municipal disposal sites and due to poor and ineffective management, the dumpsites turn to sources of environmental and health hazards to people living in the vicinity of such dumps.

Statistics on present housing condition and accesses to amenities are important factors in establishing housing policy and for the formation and evaluation of housing programs. ${ }^{3}$ Identification of needy households is necessary to effectively target the beneficiaries under various poverty alleviation programmes being implemented by the Central and the State Governments. ${ }^{4}$

\section{Objectives}

1. To assess the housing conditions of the semi urban area (Field practice area of KSHegde M edical Academy).

2. To associate these housing conditions with Education and Socio Economic Status.

\section{Methodology}

A cross-sectional study was done by purposive sampling of 
40 households in Kuthar and M anjanady, the field practise area of K.S.Hegde Medical Academy under GRAMA KSHEM A project and the questionnaire was introduced by the students after training.

\section{M ethod of data collection}

The data was collected by house to house visit, and the available person preferably head of the family was interviewed. The students pursuing 2nd year M BBS in $\mathrm{KS}$ Hegde Medical Academy, Mangalore were recruited for questionnaire administration after adequate orientation.

Verbal consent for participation in the study was taken.

Information regarding type of house, rooms, floor, kitchen, ventilation,overcrowding was scored and Housing condition was graded as Poor, Good and Excellent. Then Housing Condition was compared with Education, Occupation and Socio economic status.

\section{Statistical analysis}

Data entry and management was done in excel. The data sets were transferred into SPSS after data cleaning and recoding with data definitions. Descriptive analysis was done and Percentages were calculated to represent the data.

\section{Ethical Considerations}

The following ethical issues were considered for this study:

1. No physical harm for the participants as there was no intervention.

2. Confidentiality will be maintained throughout the study by coding the data.

3. Verbal consent was obtained from all the participants before participating in the study.

\section{Resultsand Discussion}

A total of 40 households were interviewed in the two areas. Majority of the households belonged to the Muslim religion.

\section{Some Aspects of Facilities for Living}

1.1 Drinking water facility during last 365 days. Pipe water serves $65 \%$ of Water requirement of the community, Sanitary well serves $27.5 \%$ and
Insanitary well $7.5 \%$ as shown in Table 1.The three sources of drinking water, 'tap', 'tube well/hand pump' and 'well' together

served nearly 97 per cent of rural households and 95 per cent of urban households.

1.2 Sanitation facility.

In our study all the households (100\%) had latrine facility which was used by all the members of the house. This is in contrast to the survey ${ }^{1}$ (NSS Report No. $535(65 / 1.2 / 1))$ which found that 11 per cent of urban households did not haveany latrine.

1.3 Electricity facility.

All households (100\%) had electricity for lighting and other purposes. At the all-India level, 96 per cent inurban areas had this. ${ }^{1}$

1.4 Households with three basic facilities: drinking water within premises, latrine and electricity Nearly $65 \%$ of households had all three facilities. According to NSS survey all three facilities wereenjoyed by 68 per cent households. ${ }^{1}$

1.5 Tenuretypes

A majority of the households were residing in owned dwelling (95\%) Table 2. Nearly 62 per cent in urban area people lived in own dwelling.

\section{Characteristics of the house and dwelling unit.}

2.1 Type of structure.

Nearly $55 \%$ of households lived in pucca houses, $42.5 \%$ lived in Semi-pucca houses and only $2.5 \%$ lived in Katcha houses. Refer Table 3.According to NSS Survey 92 per cent of the urban households lived in pucca structures, 6 per cent of the urban households lived in semi-pucca structures and 2 per cent of the urban households.

\section{Micro environmental elements surrounding the house}

Fifteen percent of households had Good methods of Waste Disposal, 35\% had Acceptable methods and $50 \%$ had Poor methods of disposal(Table 4).Where as in NSS Survey Garbage disposal arrangement was available to 79 per cent of the urban households. ${ }^{1}$ 


\section{Waste Disposal Methods.}

Almost all the population in Class $\mathrm{V}$ had poor method of Waste disposal. 9\% of Class IV population had good M ethods of disposal.

Majority of the population had poor methods of disposal.

Thirty four percent of the graduates had good methods of waste disposal. Majority of post high school population and middle school population had acceptable methods of waste disposal.(Fig1)

\section{Vector control measures.}

As shown in Table 5, $40 \%$ of the households with vector breeding potential had appropriate measures for vector control whereas the rest $60 \%$ had inappropriate measures.Fifty two percent of households had controlled vectors by using appropriate methods.

\section{Ventilation and Overcrowding.}

Sixty seven percent of Class V population and 24\% of Class IV managed to have No Overcrowding. All Christians were found to have No Overcrowding. $37 \%$ of M uslims and $22 \%$ of Hindus had M oderate Overcrowding.Almost all Graduates were found to have No Overcrowding. Whereas all professionals had M oderate Overcrowding.

Ventilation was adequate among all Class V, Class III and Class I population, Professionals, Graduates and High school population, all Christians,89\% of Muslims and $77 \%$ of Hindus.(Fig 2)

\section{Housing Conditions.}

Among the houses with Excellent conditions majority were Educated upto Middle school and High school(66.6\%), followed by Graduates (25\%).(Fig 3 )

Twenty Five Percent of Class IV population managed to have Excellent Housing conditions. (Fig 3 )

Among the houses with Excellent conditions majority were Muslims(75\%), followed by Hindus(16.7\%) and Christians(8.3\%). Among the houses with Poor conditions $90.9 \%$ were M uslims and $9.1 \%$ were Christians. (Fig 4 )

$33.3 \%$ of unskilled workers and clericalworkers also managed to have excellent housing

Table : 1

\begin{tabular}{|l|c|}
\hline Water source & Percent \\
\hline Pipe Water & 65.0 \\
\hline Sanitary Well & 27.5 \\
\hline Insanitary Well & 7.5 \\
\hline \multicolumn{2}{|l}{ conditions(Fig 4) }
\end{tabular}

Table : 2

\begin{tabular}{|l|c|}
\hline & Percent \\
\hline Own & 95.0 \\
\hline Rented & 5.0 \\
\hline Total & 100.0 \\
\hline
\end{tabular}

Table : 3

\begin{tabular}{|l|c|}
\hline & Percent \\
\hline Pucca & 55.0 \\
\hline Semipucca & 42.5 \\
\hline Katcha & 2.5 \\
\hline Total & 100.0 \\
\hline
\end{tabular}

Table : 4

\begin{tabular}{|l|c|}
\hline & Percent \\
\hline Poor & 50.0 \\
\hline Acceptable & 35.0 \\
\hline Good & 15.0 \\
\hline
\end{tabular}

Table : 5

\begin{tabular}{|l|c|c|c|}
\hline \multirow{3}{*}{$\begin{array}{l}\text { Insect Breeding } \\
\text { Sites }\end{array}$} & & \multicolumn{2}{|c|}{ Preventive Measures } \\
\cline { 3 - 4 } & & Appropriate & Inappropriate \\
\cline { 2 - 4 } & Present & $40 \%$ & $60 \%$ \\
\cline { 2 - 4 } & Absent & $52 \%$ & $48 \%$ \\
\hline
\end{tabular}

Preventive measures like Dry Day, M osquito Nets, etc.

\section{Conclusion}

It was found that majority of the population had good housing conditions. Education and Socio economic status has an impact on Housing condition.

\section{Acknowledgements}

The authors would like to thank Mr Santhosh and M r Ravi, Medico social workers, Department Of Community Medicine and the students of II MBBS for helping in the data collection. 
Fig. 1

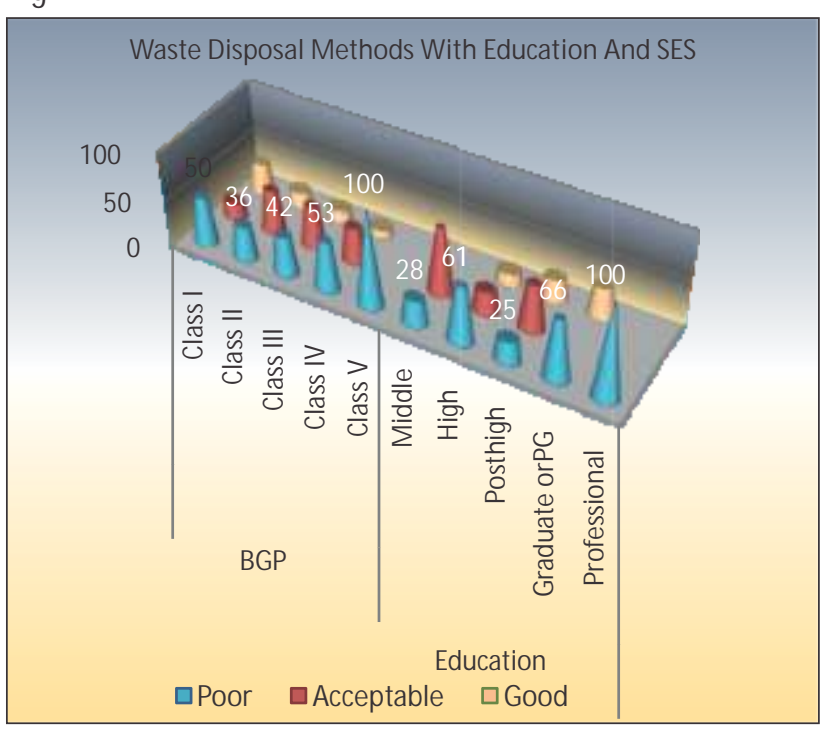

Fig. 3

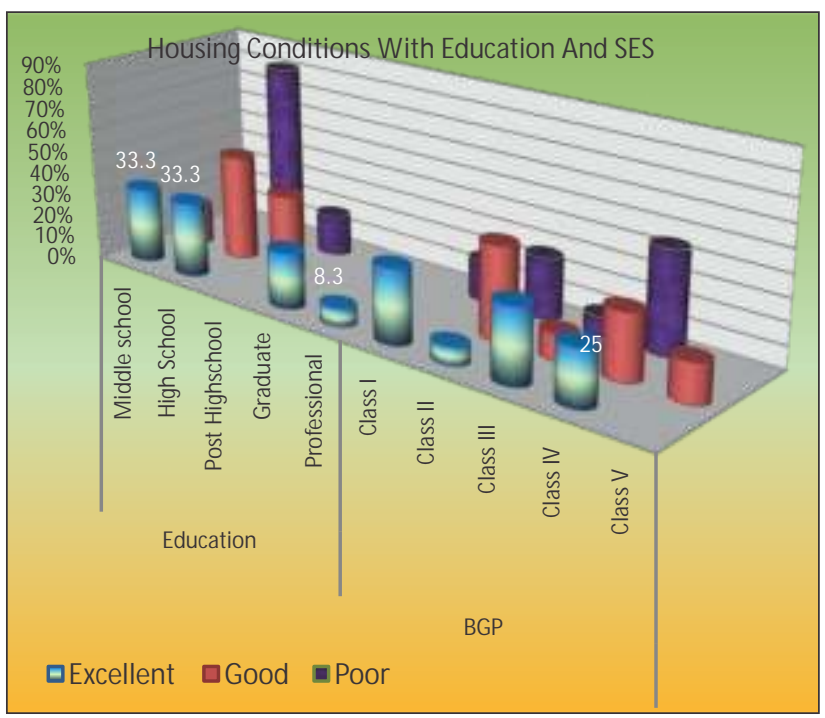

\section{References}

1. NSS Report No. 535: Housing Condition and Amenities in India: July, 2008-June, 2009

2. Housing Shortages in Rural India Shamsher Singh, Madhura Swaminathan, and V. K. Ramachandran.

3. Report on 65th Round NSS, Department of Economics \& Statistics, Kerala.

4. The Impact of Overcrowding on Health and Education: A review of the Evidence and Literature.

5. Report of the expert group to recommend the detailed methodology for identification of families below poverty line in urban areas.

6. Socioeconomic Status and Health:Dimensions and M echanismsDavid M. Cutler, Harvard University and NBERAdriana Lleras-Muney, Princeton University and NBERTom Vogl, Harvard University;October 2008.
Fig. 2

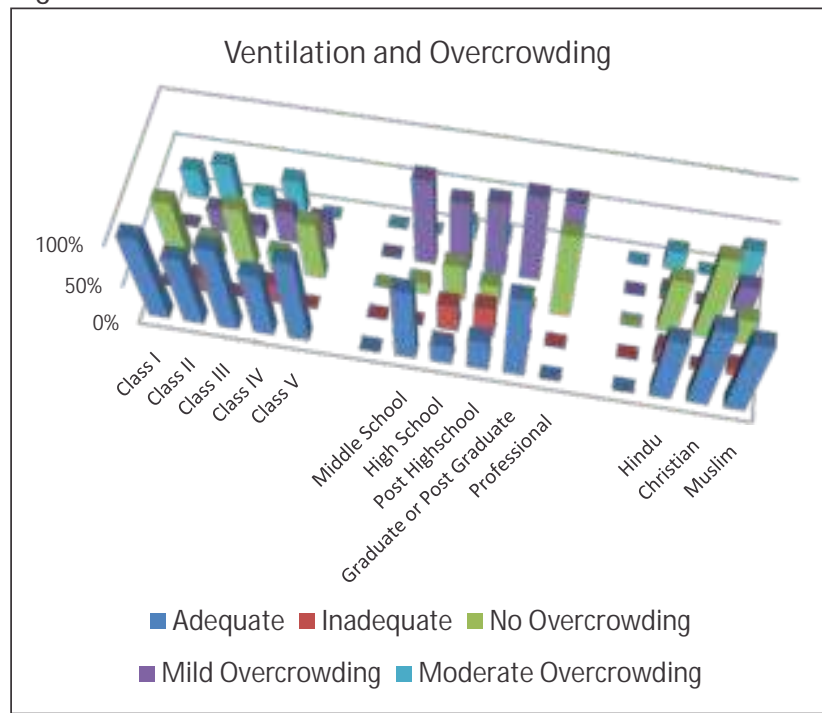

Fig. 4



